\title{
Degradabilidad in situ de la dieta seleccionada por la llama (Lama glama)
}

\author{
In situ degradability of the diet selected by the llama (Lama glama) \\ Degradabilidade in situ da dieta selecionada pela Ihama (Lama glama)
}

Wilson Ponce Quispe

wilzonponce@hotmail.com

\section{Flavio Eudaldo Merlo Maydana}

flamema@gmail.com

Universidad Pública de El Alto, Bolivia

Artículo recibido enero 2020, arbitrado febrero 2020 y publicado en mayo 2020

\section{RESUMEN}

Por efectos de la degradación y baja producción de pastos naturales, se presume no se cubren los requerimientos nutricionales de la llama. El objetivo de la investigación fue evaluar la degradabilidad in situ de materia seca (DISMS), de proteína bruta (DISPB), fibra detergente neutra (DISFDN) y fibra detergente ácida (DISFDA), de la dieta seleccionada por llamas según meses y tiempos de incubación, en la comunidad Jila Huta Manasaya, Sajama Oruro. Se seleccionaron 4 llamas machos de 3 años de edad, tipo q'ara de 70 $\mathrm{kg} / \mathrm{llama}$; de tamas de la comunidad en los que fueron aplicadas mediante cirugía implante de cánulas en el primer compartimento (C1). Las muestras de ingesta colectada a nivel esofágica de llamas pastoreadas en pastizales naturales fueron secadas, molidas, almacenadas $3 \mathrm{~g}$ en bolsas Dacron de 1700 poros/cm2 no digeribles, luego incubadas en el C1 durante $0 ; 6 ; 12 ; 24 ; 36 ; 48 ; 72$, y 96 horas en los meses de octubre, noviembre y diciembre. Las técnicas de análisis de laboratorio empleadas son el análisis proximal de Weende y análisis de Van Soest. Los datos fueron analizados con arreglo factorial $3 * 8$ en diseño completamente al azar y las diferencias mediante la prueba de comparación de medias de Duncan. Los resultados obtenidos fue la degradabilidad in situ se da en un proceso y velocidad lento en el primer compartimento del estómago de llamas.

Palabras clave: degradabilidad in situ; nutrición; llamas, proteínas, materia seca

\begin{abstract}
Due to the effects of degradation and low production of natural grasses, it is presumed that the nutritional requirements of the flame are not covered. The objective of the research was to evaluate the in situ degradability of dry matter (DISMS), crude protein (DISPB), neutral detergent fiber (DISFDN) and acid detergent fiber (DISFDA), of the diet selected by flames according to months and times of incubation, in the Jila Huta Manasaya community, Sajama Oruro. Four 3-year-old male llamas, q'ara type of $70 \mathrm{~kg} /$ llama, were selected; of community sizes in which they were applied by surgery to implant cannulas in the first compartment (C1). The samples of ingestion collected at the esophageal level of llamas grazed in natural grasslands were dried, ground, stored 3 $\mathrm{g}$ in Dacron 1700 pore / $\mathrm{cm} 2$ non-digestible bags, then incubated in $\mathrm{C} 1$ for $0 ; 6 ; 12 ; 24 ; 36 ; 48 ; 72$, and 96 hours in the months of October, November and December. The laboratory analysis techniques used are the proximal Weende analysis and Van Soest analysis. The data were analyzed with a $3 * 8$ factorial arrangement in a completely randomized design and the differences using the Duncan mean comparison test. The results obtained were the degradability in situ occurs in a slow process and speed in the first compartment of the llama stomach.
\end{abstract}

Key words: in situ degradability; nutrition; flames, proteins, dry matter

Alfa, Revista de Investigación en Ciencias Agronómicas y Veterinarias Vol. 4, Nro. 11, Mayo - Agosto 2020 


\section{RESUMO}

Devido aos efeitos da degradação e pela baixa produção de gramíneas naturais, presume-se que os requisitos nutricionais da chama, não estão sendo alcançados. 0 objetivo da pesquisa foi avaliar a degradabilidade in situ de matéria seca (DISMS), proteína bruta (DISPB), fibra em detergente neutro (DISFDN) e fibra em detergente ácido (DISFDA), da dieta selecionada por chamas de acordo com meses e tempos de incubação, na comunidade Jila Huta Manasaya, Sajama, Oruro. Foram selecionados quatro lhamas masculinos de 3 anos de idade, tipo q'ara de Tamas, de $70 \mathrm{~kg} /$ lhama. Foram implantadas por cirurgia cânulas no primeiro compartimento (C1). As amostras de ingestão coletadas no nível esofágico de lhamas pastadas em pradarias naturais foram secas, moídas, e armazenadas cada $3 \mathrm{~g}$ em sacos não digeríveis Dacron 1700 poros / $\mathrm{cm} 2$ e incubadas em C1 por $0 ; 6 ; 12$; $24 ; 36 ; 48 ; 72$ e 96 horas, nos meses de outubro, novembro e dezembro. As técnicas de análise laboratorial utilizadas são a análise proximal de Weende e a análise de Van Soest. Os dados foram analisados em arranjo fatorial $3 * 8$, em delineamento inteiramente casualizado, e as diferenças, utilizando o teste de comparação de médias de Duncan. Os resultados obtidos foram que a degradabilidade in situ e a baixa velocidade acontecem no primeiro compartimeno do estômago da lhama.

Palabras clave: degradabilidade in situ; nutrição; chamas; proteínas; matéria seca

\section{INTRODUCCIÓN}

En las regiones alto andinas de Bolivia, la crianza de llamas se constituye en el principal medio de vida de 53.078 familias campesinas (FAO, 2005); con una población nacional de 2.529.942 animales (SENASAG Catastro Pecuario, 2011). Beneficia con la oferta de carne y fibra a miles de familias de los barrios marginales de las principales ciudades de La
Paz, Oruro, Potosí, Cochabamba, y Sucre (Ticona y Defilippis, 1995).

Actualmente la actividad ganadera de la crianza de llamas, atraviesa un problema en la degradación de los recursos naturales (expresada en la baja producción de fitomasa en condiciones regulares del comportamiento climático, edáfico y otros), como consecuencia la vegetación no cubre los requerimientos de consumo de materia seca y menos los nutrientes para la ganadería de esta región.

La alimentación de llamas se basa en el pastoreo en campos nativos que crecen en altiplanicies alto andinas, constituyendo la principal fuente de forraje para la llama, se estima que más del $98 \%$ de los pastizales en el altiplano, están constituidas por especies nativas y $2 \%$ de especies forrajeras introducidas (Ayala y Aranda, 1999).

En la alimentación el factor primordial es el poder de asimilación de nutrientes, porque el rendimiento de la producción animal depende de la cantidad, calidad del forraje consumido y del coeficiente de digestibilidad de los alimentos.

La información sobre digestibilidad de nutrientes en esta especie es relativamente escasa. Sin embargo, existe concordancia entre los diversos autores en que son más eficientes que otras especies de rumiantes, como el ovino, en especial, en dietas de baja calidad caracterizadas por su bajo contenido proteico y elevado contenido de paredes celulares.

La digestibilidad es un parámetro importante en la evaluación del valor nutritivo del forraje, debido a que mide el grado de utilización digestiva de un alimento. En este sentido, los estudios de digestibilidad In situ se presentan como una alternativa factible para la evaluación de forrajes. 
El propósito de este estudio fue evaluar la degradabilidad in situ de la dieta seleccionada por las llamas (Lama glama) fistuladas en el primer compartimento según meses y tiempos de fermentación, en la comunidad Jila Huta Manasaya de la provincia Sajama del departamento de Oruro, a fin de determinar la degradabilidad in situ de materia seca (M.S.) de la dieta seleccionada por llamas pastoreadas en praderas nativas; la degradabilidad in situ de proteína bruta (P.B.) de la dieta seleccionada por llamas pastoreadas en praderas nativas según meses y tiempos de fermentación, también, la degradabilidad in situ de fibra detergente neutra (F.D.N.), de la dieta seleccionada por llamas pastoreadas, por último también determinar la degradabilidad in situ de fibra detergente ácida (F.D.A.), de la dieta seleccionada por llamas pastoreadas en praderas nativa.

Los camélidos sudamericanos son especies muy importantes en la economía andina; por constituir fuente de carne, fibra y trabajo para los criadores que habitan las zonas alto andinas por encima de los 4.000 m.s.n.m., estos animales utilizan extensas áreas de praderas naturales, que debido a factores asociados a la altitud no podrían ser aprovechadas de manera eficiente por otros animales domésticos (Novoa y Flores, 1991).

Los camélidos sudamericanos, son los más significativos desde el punto de vista social, económico, ecológico y estratégico. Tiene importancia social porque miles de familias se dedican a la crianza y explotación, son la principal fuente de sustento, ingreso económico y satisfacción de sus necesidades vitales; también se considera dentro de este rubro la comercialización, la artesanía y la industrialización (Solís, 2000).

En la cadena productiva de los camélidos, las actividades económico - productivas se inician en la crianza de llamas y alpacas en unidades de producción familiar, de cuya administración productiva y luego del desarrollo de las actividades productivas básicas de esquila y extracción, se da origen a la estructura y funcionamiento de las cadenas productivas de la fibra, carne y cuero (Cardozo, 2007).

\section{MATERIALES Y MÉTODOS}

De acuerdo a la clasificación de la investigación según su propósito se enmarcó dentro de un estudio cuantitativo. De acuerdo a la localización del área de investigación se realizó en la zona Huacullani, comunidad Jila Huta Manasaya, del municipio Curahuara de Carangas, de la provincia Sajama, departamento de Oruro, entre las coordenadas, 17³9'29.2" Latitud Sur y 68 $24^{\prime} 09.2^{\prime \prime}$ Longitud Oeste a una altitud de 3892 m.s.n.m. y distante a $173 \mathrm{~km}$ desde el departamento de La Paz. Con características fisiográficas y ecosistema del lugar del estudio fue en el territorio municipal de Curahuara de Carangas, que corresponde a la fisiografía de la cordillera occidental o volcánica, localizada entre la serranía Saucarí hacia el oriente y la cordillera occidental, ramal cordillera de Pacajes hacia el occidente. Fisiográficamente, presenta serranías interplánicas, correspondientes a las serranías de Saucarí, conformada por cerros, colinas, serranías y altas mesetas, integradas con llanuras extensas altas y bajas (PDM Curahuara de Carangas, 2011). El territorio municipal de Curahuara de Carangas, se constituye en el área de aporte de las cuencas del río Desaguadero y del salar de Coipasa; que en conjunto forman parte de la cuenca endorreica del altiplano. Los suelos del municipio de Curahuara de Carangas, en general corresponden a los órdenes: Entisol, Inceptisol con asociaciones de Histosoles y

Alfa, Revista de Investigación en Ciencias Agronómicas y Veterinarias Vol. 4, JNro. 11, Mayo - Agosto 2020 
Aridisoles (PDM Curahuara de Carangas, 2011).

\section{Principales especies de flora $y$ fauna del lugar de estudio}

Existen especies de flora cuya distribución es restringida por encontrarse en situación de amenaza; estas especies son: Yareta (Azorella compacta), Keñua (Polylepis tarapacana), Tola (Parastrephia lepidophylla y Baccharis incarum). Estas especies son consideradas en protección y reguladas por el sistema Nacional de Áreas Protegidas (SNAP), las medidas de protección son implementadas por la dirección del parque nacional Sajama (PDM Curahuara de carangas, 2011).

La fauna en el territorio municipal de Curahuara de Carangas es típica de la región; sin embargo, es mucho más diversa en el área del parque nacional Sajama, sin que ello signifique que algunas especies también estén presentes en el resto del territorio (plan de manejo del área natural de manejo integral del parque nacional Sajama, 1996).

\section{Cánulas para el primer compartimento}

Se utilizaron cánulas semiflexibles que consisten en un tubo PVC con un diámetro de $7 \mathrm{~cm}$. cuyos extremos se cubren con dos ponchillos de goma para fijarlas entre el primer compartimento, (peritoneo) y otro con la piel. La cánula se aseguró con un tapón sujetado con pasador metálico en la parte externa (Bautista, 1999).

\section{Métodos}

\section{Definición del lugar de estudio}

El lugar de estudio elegido, fueron los campos naturales de pastoreo ubicados en la comunidad Jila Huta Manasaya; sobre una superficie de 171 hectáreas; donde se realizó las obtenciones de muestra durante los meses de octubre, noviembre y diciembre, bajo el siguiente diagrama de flujo.

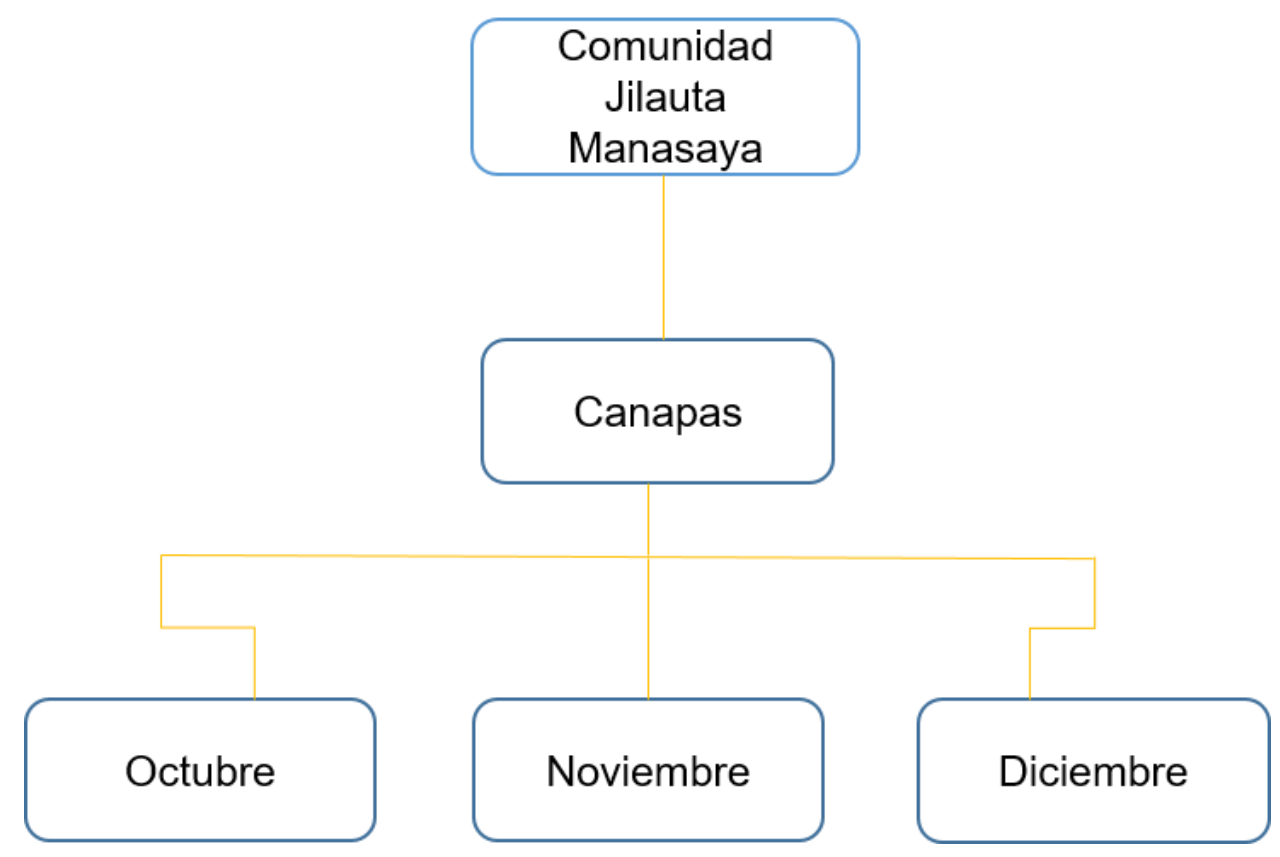

Figura 2. Estructura del diagrama de flujo del estudio

Alfa, Revista de Investigación en Ciencias Agronómicas y Veterinarias Vol. 4, N Nro. 11, Mayo - Agosto 2020 


\section{Selección de animales}

Se seleccionaron 4 llamas machos de 3 años de edad, tipo q'ara con un peso promedio de $70 \mathrm{~kg} / \mathrm{llama}$; de las tamas de comunidades de la primera sección municipal de Curahura de Carangas de la provincia Sajama del departamento de Oruro, bajo los siguientes criterios:

- La edad se estimó por cronología dentaria mediante el boqueo y corroborado por la información de los productores.

- Animales con buenas condiciones de salud, sin defectos congénitos ni hereditarios y buena condición corporal, que fueron seleccionadas a través del examen físico.
- Los animales seleccionados se reubicaron en la comunidad de Jila Huta Manasaya para la adaptación a la tama que pastorean en el lugar de estudio, posteriormente fueron intervenidos quirúrgicamente y se efectuaron los cuidados post operatorios.

\section{Muestreo de la dieta seleccionada por llamas}

En cuanto al material de estudio para el presente trabajo se utilizó la ingesta de 3 llamas canuladas a nivel esofágica, la misma proviene de la investigación realizada por Villca, (2013). La composición florística de la ingesta fue con mayor proporción de gramíneas, como especies de mejor preferencia (Cuadro 3).

Cuadro 3. Especies de mayor preferencia colectada a nivel esofágico de las llamas

\begin{tabular}{lllll}
\hline \multirow{2}{*}{ Familias } & \multicolumn{4}{c}{ Meses de Estudio } \\
& Octubre (\%) & Noviembre (\%) & Diciembre (\%) & Media (\%) \\
\hline Poacea & 65 & 71 & 59 & 65 \\
Rosaceae & 14 & 10 & 11 & 12 \\
Fabaceae & 6 & 9 & 14 & 10 \\
Asteraceae & 8 & 3 & 4 & 5 \\
Malvaceae & 4 & 3 & 6 & 4 \\
Cyperaceae & 1 & 4 & 4 & 3 \\
Geraniaceae & 2 & 0 & 2 & 1 \\
\hline Fuen & & & &
\end{tabular}

Fuente: Villca, (2013)

Los pastos de mayor preferencia fueron las siguientes familias botánicas nativas $\mathrm{y}$ proporciones: Poacea, 65\%, Rosaceae, 12\%, Fabaceae, 10\%, Asteraceae, 5\%, Malvaceae,
4\%, Cyperaceae, 3\% y Geraniaceae, 1\% con menor proporción en relación al 100\% del contenido de la composición botánica de la ingesta de la llama. (Cuadro 3) 


\section{Preparación de la muestra}

La muestra de la ingesta colectada a nivel esofágica de llamas pastoreadas en pastizales naturales durante los meses de octubre, noviembre y diciembre (2013), fueron secadas al medio ambiente bajo sombra y luego en estufa a una temperatura de $65^{\circ} \mathrm{C}$ por un tiempo de 48 horas.

La ingesta en su fase seca fue sometida a molienda en un mortero hasta obtener partículas de 2 a 4 milímetros, de estas se prepararon muestras de 3 gramos que fueron depositados en bolsas de Dacron no digestibles de 14 X 17 centímetros de tamaño con una densidad de 1700 poros $/ \mathrm{cm}^{2}$, cada bolsa con muestra fue codificada para su identificación.

\section{Degradabilidad en el primer compartimento}

Las muestras se introdujeron en las mallas para ser incubadas en el compartimento uno (C1), para este paso fueron remojadas en agua tibia para favorecer el contacto con el medio. Este procedimiento se repitió para cada bolsa a su correspondiente horario y cumpliendo rigurosamente con los tiempos de incubación.

Los tiempos de fermentación de las muestras en el primer compartimento (C1) fueron de; $0 ; 6 ; 12 ; 24 ; 36 ; 48 ; 72$, y 96 horas (4 días), en total se han distribuido en 4 días/mes durante los tres meses de estudio.

La secuencia de la colocación de las muestras al primer compartimento, fue en el orden de 96; 72; 48; 36; 24; $12 ; 6$ y 0 horas, todas en una red de cáñamo $(35 \times 30)$ aseguradas a la cánula del primer compartimento con una cuerda de nylon de $40 \mathrm{~cm}$, con un intervalo de 5 minutos de llama a llama para evitar el error de tiempo de fermentación. La extracción de las muestras fue en conjunto para cada llama y de llama a llama con un intervalo de 5 minutos de la misma forma como se ha introducido las bolsas con muestra.

\section{Tratamiento final de la degradabilidad}

Cumplidos los horarios de la degradabilidad, las mallas con las bolsas en su interior se lavaron con agua fría, para eliminar las impurezas de la superficie de las bolsas. Para éste lavado se realizó cuatro enjuagues, hasta que las bolsas quedaron limpias y sin residuos, luego se procedió al oreo y secado en estufa a $65^{\circ} \mathrm{C}$ por 48 horas o hasta estabilizar el peso seco de las muestras. Posteriormente se pesó en una balanza de precisión, para luego sellar en envases nylon con su correspondiente identificación o etiquetado para el análisis de laboratorio.

\section{Muestra}

Se establece en la aplicación de las muestras en el primer compartimento según horas de fermentación, del material vegetativo obtenido de la dieta seleccionada por la llama durante el pastoreo.

\section{Factores de estudio}

Los factores de estudio en la presente investigación son:

- Meses de evaluación: Octubre, Noviembre y Diciembre.

- Tiempo de fermentación: $0 ; 6 ; 12 ; 24$; 36; 48; 72 y 96 horas

\section{Variables de respuesta}

Las variables de respuesta que se consideraron en la degradabilidad in situ en llamas son:

- Degradabilidad in situ de materia seca (DISMS): \% 
- Degradabilidad in situ de proteína bruta (DISPB): \%

- Degradabilidad in situ de fibra detergente neutra (DISFDN): \%

- Degradabilidad in situ de fibra detergente ácida (DISFDA): \%

\section{Análisis de laboratorio}

Una vez realizado el ensayo de la degradabilidad in situ en las llamas, las muestras fueron remetidos al laboratorio de nutrición animal de la Universidad Mayor de San Simón, Facultad de Ciencias Agrícolas y Pecuarias, para determinar su composición química donde se realizaron el análisis proximal de Weende para materia seca constante y proteína bruta, y análisis de Van Soest para la fibra detergente neutra y fibra detergente ácida.

\section{Diseño experimental}

La interpretación de resultados de los parámetros (materia seca, proteína bruta, fibra detergente neutra y fibra detergente ácida), se efectuaron mediante el análisis Factorial de $3 * 8=24$ tratamientos (con 4 repeticiones) utilizada mediante el diseño completamente al azar y cuyo modelo lineal es la siguiente (Rodríguez y Cardozo, 1989).

$$
Y i j=\mu+\alpha i+\beta j+\alpha \beta i j+\varepsilon i j
$$

Donde:

$Y i j=$ Variable de respuesta

$\mu=$ Media general

$\alpha i=\quad$ Efecto de $i-$ esimo nivel meses

$\beta j=$ Efecto de $j-$ esimo nivel horas

$\alpha \beta i j=$ Efecto de la interacción $i j-$ esimo

$\varepsilon i j=$ Error experimental

Las diferencias estadísticas fueron analizados con la prueba de comparación de medias Duncan con un nivel de significancia $(\alpha=0,05)$.

\section{RESULTADOS Y DISCUSIÓN}

En este apartado son mostrados algunos de resultados arrojados durante el desarrollo de este estudio. En la investigación los resultados (Tabla 1), muestran que la digestibilidad in situ se encuentran afectadas por los factores meses y tiempos de fermentación $(\mathrm{P}<0,01)$, el coeficiente de variación de 7,59\% indica que los datos obtenidos son confiables. Se rechaza la hipótesis nula planteada para los factores meses de evaluación y tiempos de fermentación.

Tabla 1. ANVA para la degradabilidad in situ de materia seca de la dieta seleccionada por llamas

\begin{tabular}{lrrrrr}
\hline Fuente & G.L. & S.C. & C.M. & Fc. & Pr $>$ F \\
\hline Meses & 2 & 60,3801 & 301,9006 & 23,5200 & $<, 0001^{* *}$ \\
Tiempos de fermentación & 7 & $2.660,0744$ & $3.800,1062$ & 296,0000 & $<, 0001^{* *}$ \\
Interacción & 14 & 469,4282 & 33,5306 & 2,6100 & $0,0069^{* *}$ \\
Error experimental & 48 & 616,2357 & 12,8382 & & \\
\hline TOTAL & $\mathbf{7 1}$ & $\mathbf{2 8 . 2 9 0 , 2 0 8 6}$ & & & \\
\hline
\end{tabular}

C.V. $=7,59 \%$ 


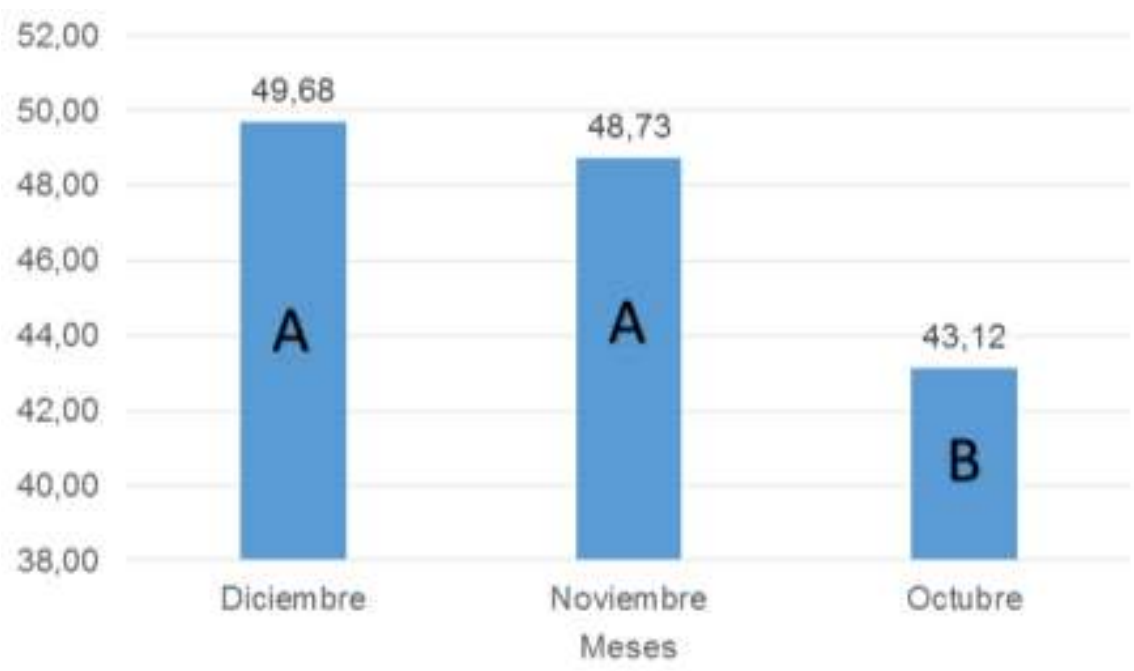

Gráfico 1. Comparación de medias Duncan de la degradabilidad in situ de materia seca de la dieta seleccionada por llamas según meses

La comparación de medias Duncan (Gráfico 1), muestra que la degradabilidad de materia seca en llamas pastoreadas en praderas nativas, son similares y superiores estadísticamente para los meses de diciembre y noviembre con 49,68\% y 48,73\%, e inferiores en el mes de octubre con 43,12\%. Los niveles superiores de la degradabilidad in situ de materia seca en los meses de noviembre y diciembre probablemente se deba a que los pastos se encuentran en el estado de rebrote, estos forrajes tiernos se caracterizan por su mayor degradabilidad. En el mes de octubre con precipitaciones pluviales mínimas los pastos se caracterizan por su estado de madurez fisiológica y seca que determinan la menor degradabilidad.

En llamas la degradabilidad in situ de materia seca está relacionado con la selectividad de su dieta. El consumo de las especies gramíneas del mes octubre a diciembre tiene una variación ascendente donde la degradabilidad es inversamente proporcional, del mes de octubre a diciembre tiene una tendencia a ascenso de menor a mayor degradación esto está relacionado con el consumo de graminoides, hierbas y arbustos (Villca 2013).

Choque y Magne (1996), reportan la digestibilidad de Festuca orthophylla en la época seca en llamas y ovinos, 41,30 y 39,40\% respectivamente, los cuales son inferiores a los encontrados en el estudio. Cardozo (1991), reporta valores de digestibilidad de materia seca de Stipa ichu en llamas 51,46\%; $65,94 \%$ y $59,49 \%$, superiores a los obtenidos en el presente trabajo. 
Tabla 2. Comparación de medias Duncan de la degradabilidad in situ de materia seca de la dieta seleccionada por llamas según tiempos de fermentación (\%).

\begin{tabular}{lccc}
\hline & Grupo Duncan & Media (\%) & Factor tiempos de fermentación (Hrs) \\
\hline A & & 71,09 & 96 \\
A & 68,45 & 72 \\
\multicolumn{2}{c}{ B } & 63,38 & 48 \\
\multicolumn{2}{c}{ C } & 55,37 & 36 \\
\multicolumn{2}{c}{ D } & 41,12 & 24 \\
\multicolumn{2}{c}{ E } & 32,75 & 12 \\
\multicolumn{2}{c}{ F } & 26,03 & 6 \\
\multicolumn{2}{c}{ G } & 17,89 & 0 \\
\hline
\end{tabular}

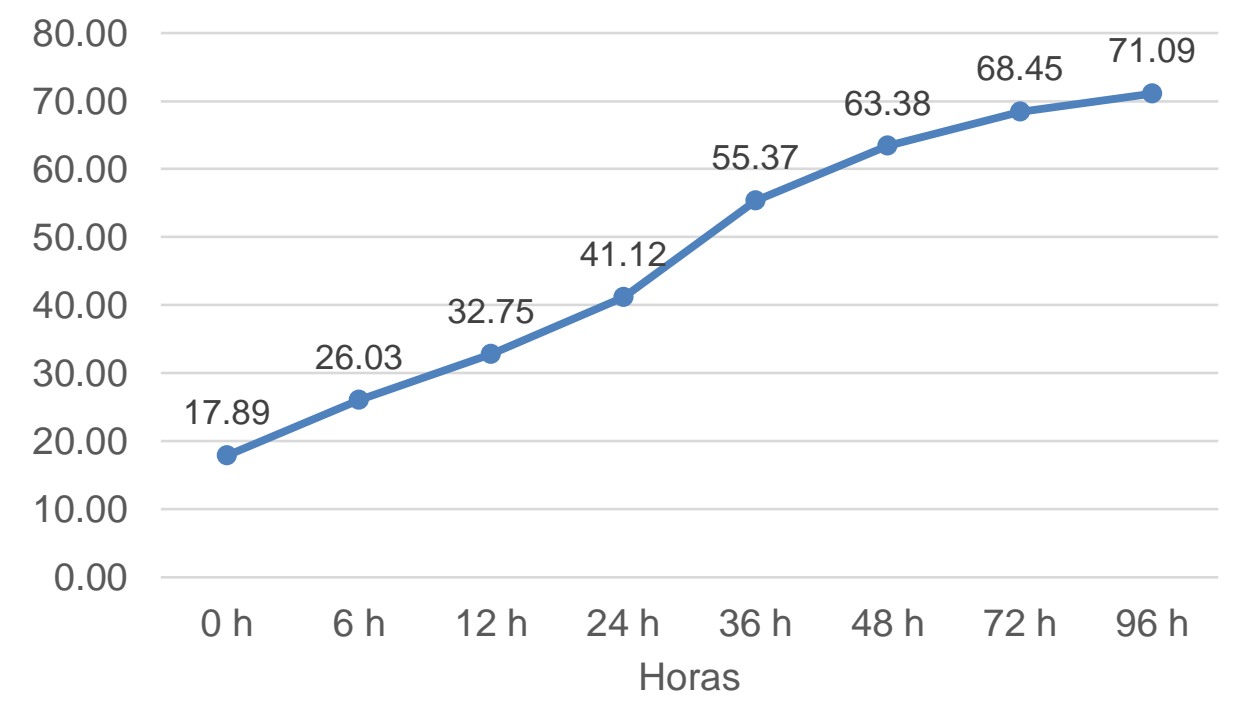

Gráfico 2. Comparación de medias Duncan de la degradabilidad in situ de materia seca de la dieta seleccionada por llamas según tiempos de fermentación

La comparación de medias Duncan para el factor horas de fermentación (gráfico 2), muestra que las 96 y 72 horas son estadísticamente similares y superiores con $71,09 \%$ y $68,45 \%$, seguida por 48 horas con $63,38 \%, 36$ horas con 55,37\%, 24 horas con $41,12 \%, 12$ horas con $32,75 \%, 6$ horas con $26,03 \%$, e inferior en las 0 horas con $17,89 \%$.

La degradabilidad de materia seca en llamas pastoreadas en praderas nativas de la comunidad de Jila Huta Manasaya demuestra un proceso lento de degradación en el compartimento 1 de las llamas, probablemente por el estado de madurez fisiológica de los pastos, los niveles de degradación se incrementan progresivamente hasta las 72 horas de incubación, con tendencia a estabilizarse a partir de 72 horas. (Tabla 2).

La mayor eficiencia digestiva de los camélidos sudamericanos con alimentos de baja calidad está relacionada con el mayor tiempo de retención del alimento en su tracto digestivo. Así mismo, esta mayor eficiencia digestiva también puede deberse a las

Alfa, Revista de Investigación en Ciencias Agronómicas y Veterinarias Vol. 4, JNo. 11, Mayo - Agosto 2020 
mayores frecuencias de las contracciones del estómago y ciclos de rumia, la alta relación flujo salival y volumen estomacal, y la presencia de sacos glandulares. Estos atributos facilitarían una mayor eficiencia en la maceración, mezclado y absorción de la digesta (Church, 1994).

Los valores encontrados en el presente trabajo fueron menores a los reportados por Acho, (2003) de 75,28 \% y 71,84\% para la dieta seleccionada a las 96 y 72 horas de incubación y Ancasi (2013) para Nassella pubiflora de $70,52 \%$ y $71,43 \%$ a las 96 y 72 horas de fermentación.
Según los resultados obtenidos se corrobora que existe un proceso lento en la degradación in situ de materia seca en el compartimento 1 de las llamas, que indica un mayor tiempo de retención de alimentos y una mayor eficiencia digestiva de estos animales.

Según el análisis de varianza de efectos simples (tabla 3), la interacción entre los tiempos de fermentación de 48, 72 y 96 horas por los meses de octubre, noviembre $\mathrm{y}$ diciembre influyen en la degradabilidad in situ de materia seca de la dieta seleccionada por las llamas.

Tabla 3. ANVA de efectos simples para la interacción meses de evaluación por tiempos de fermentación de la degradabilidad in situ de materia seca de la dieta seleccionada por llamas

\begin{tabular}{lrrrrr}
\hline F. de V. & G.L. & S.C. & C.M. & F.c. & F. 0,05 \\
\hline Meses (0 hrs) & 2 & 64,5016 & 32,2508 & 2,5100 & $0,0917 \mathrm{NS}$ \\
Meses (6 hrs) & 2 & 49,7546 & 24,8773 & 1,9400 & $0,1551 \mathrm{NS}$ \\
Meses (12 hrs) & 2 & 12,6523 & 6,3261 & 0,4900 & $0,6140 \mathrm{NS}$ \\
Meses (24 hrs) & 2 & 7,1275 & 3,5637 & 0,2800 & $0,7588 \mathrm{NS}$ \\
Meses (36 hrs) & 2 & 35,1495 & 17,5747 & 1,3700 & $0,2641 \mathrm{NS}$ \\
Meses (48 hrs) & 2 & 289,2909 & 144,6454 & 11,2700 & $<, 0001^{* *}$ \\
Meses (72 hrs) & 2 & 268,0983 & 134,0491 & 10,4400 & $0,0002^{* *}$ \\
Meses (96 hrs) & 2 & 346,6547 & 173,3273 & 13,5000 & $<, 0001^{* *}$ \\
Tiempos de fermentación (octubre) & 7 & $10.566,0000$ & $1.509,4520$ & 117.57 & $<, 0001^{* *}$ \\
Tiempos de fermentación (noviembre) & 7 & $9.525,6861$ & $1.360,8123$ & 106.00 & $<, 0001^{* *}$ \\
Tiempos de fermentación (diciembre) & 7 & $6.978,3215$ & 996,9031 & 77.65 & $<, 0001^{* *}$ \\
Error & 48 & 616,2357 & 12,8382 & & \\
\hline
\end{tabular}

La comparación de medias Duncan para la interacción tiempos de incubación por meses de evaluación (Gráfico 3), muestra que el consumo de materia seca en las 48,72 y 96 horas para los meses de noviembre $y$ diciembre son similares y superiores con $67,08 \% ; 71,22 \% ; 74,24 \%$ y $67,70 \% ; 73,29 \%$; $78,58 \%$, con respecto al mes de octubre que resultó ser inferior con 55,37\%; 60,82\% y $63,79 \%$ respectivamente. 


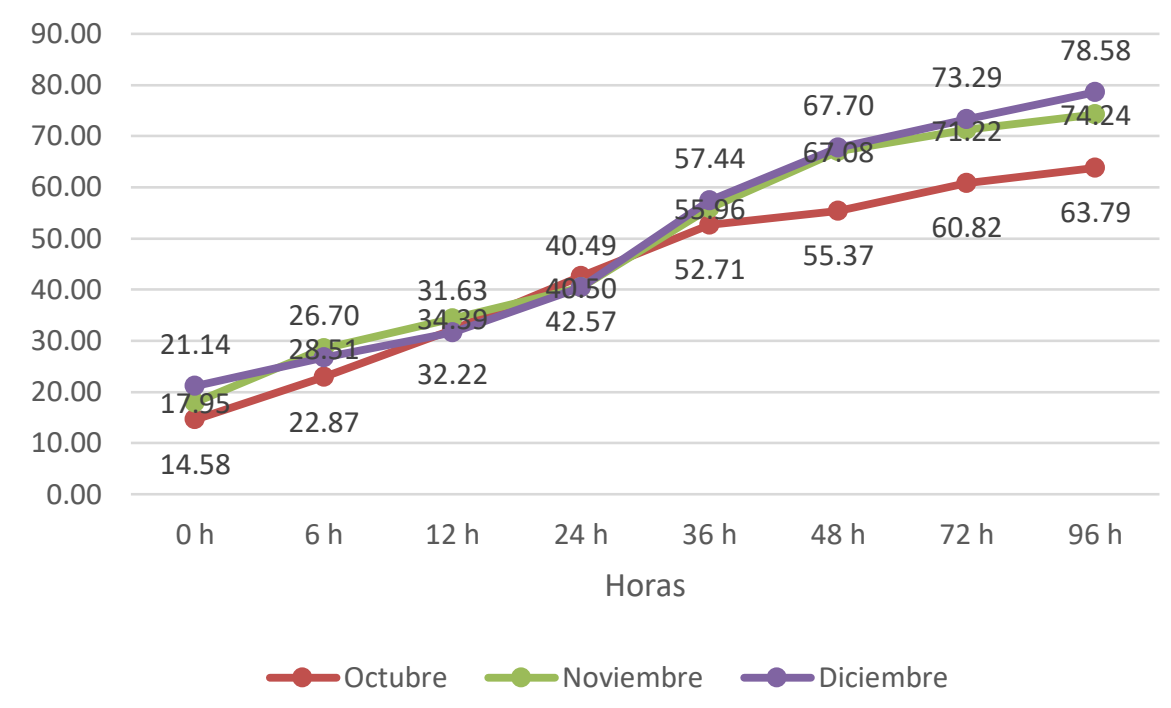

Gráfico 3. Efecto de interacción meses de evaluación por tiempos de fermentación sobre la degradabilidad in situ de materia seca de la dieta selecciona por llamas (\%).

La menor digestibilidad en el mes de octubre, probablemente se deba a que los pastos naturales tienen mayor contenido de lignina por su estado de madurez fisiológica; en los meses de noviembre y diciembre la presencia de lluvias permite el rebrote de los pastos por lo que la digestibilidad se incrementa.

La lignina ejerce un efecto negativo directo sobre la digestión total. La concentración de lignina depende de la especie de forraje, siendo mayor en las leguminosas que en las gramíneas y el estado vegetativo, a mayor madurez más lignina (Bach, y Calsamiglia, 2006).

\section{Degradabilidad in situ de proteina bruta de la dieta seleccionada por llamas}

Las proteínas son los principales constituyentes del cuerpo animal y esencial para la reparación celular y procesos de síntesis. La deficiencia proteica en la dieta conlleva a un agotamiento de las reservas en la sangre, hígado y músculos, predisponiendo al animal a una variedad de cuadros, muchos de ellos fatales (San Martin, 1999). 
Tabla 4. ANVA para la degradabilidad in situ de proteína bruta de la dieta seleccionada por llamas

\begin{tabular}{lccccc}
\hline Fuente & G.L. & S.C. & C.M. & Fc. & Pr $>$ F \\
\hline Meses & 2 & 55 & 28 & 0,7 & 0,5024 \\
Tiempos de fermentación & 7 & 38.622 & 5.517 & 138,99 & $<, 0001$ \\
Interacción & 14 & 280 & 20 & 0,5 & 0,9195 \\
Error experimental & 48 & 1.905 & 40 & & \\
\hline TOTAL & 71 & $40.862,8995$ & & & \\
\hline
\end{tabular}

C.V. $=11,49 \%$

El análisis de varianza (tabla 4), muestra que el factor tiempos de fermentación influye significativamente $(\mathrm{P}<0,01)$ sobre la degradabilidad in situ de proteína bruta. El coeficiente de variación de $11,49 \%$, indica que los datos obtenidos en el presente trabajo son confiables.

Tabla 5. Comparación de medias Duncan de la degradabilidad in situ de proteína bruta (\%) de la dieta seleccionada por llamas según tiempos de fermentación

\begin{tabular}{|c|c|c|}
\hline Grupo Duncan & Media (\%) & Factor tiempos de fermentación (Hrs) \\
\hline A & 81,07 & 96 \\
\hline A B & 79,21 & 72 \\
\hline B & 73,23 & 48 \\
\hline $\mathrm{C}$ & 63,25 & 36 \\
\hline $\mathrm{D}$ & 54,91 & 24 \\
\hline $\mathrm{E}$ & 44,96 & 12 \\
\hline $\mathrm{F}$ & 31,63 & 6 \\
\hline G & 10,52 & 0 \\
\hline
\end{tabular}

Según muestra la tabla 5, la degradabilidad in situ de proteína bruta de la dieta seleccionada por llamas son iguales y superiores a las 96 y 72 horas de fermentación, seguido por 48 horas que es similar a las 72 horas, y luego por 36; 24; 12 y 6 horas, y a las 0 horas la degradabilidad de proteína es inferior a todas las anteriores. 


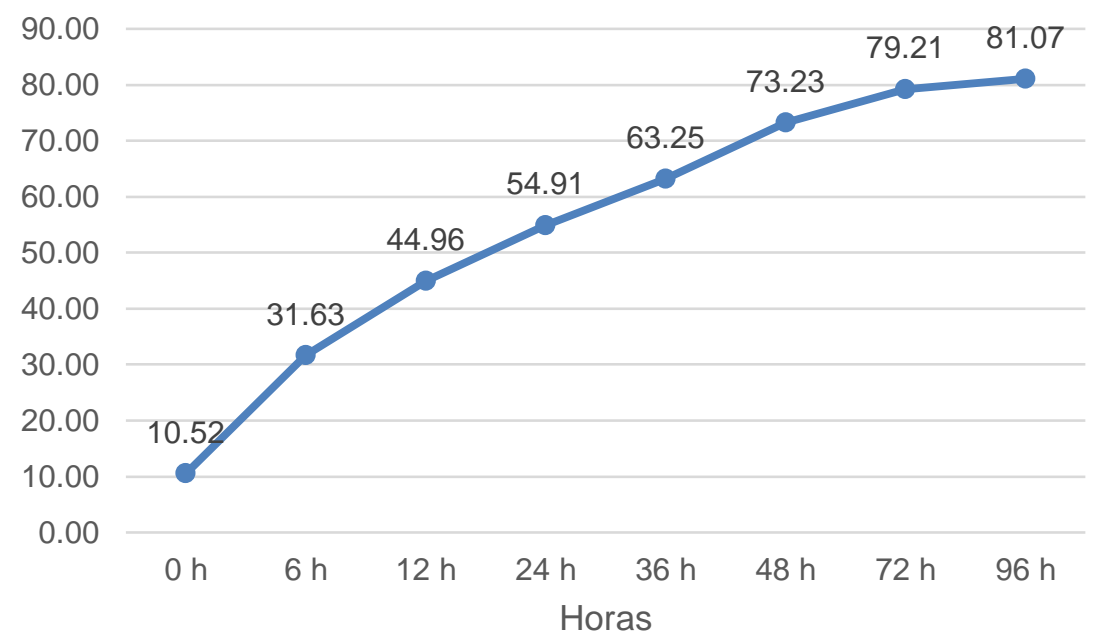

Gráfico 4. Comparación de medias Duncan para la degradabilidad in situ de proteína bruta de la dieta seleccionada por llamas según tiempos de fermentación

Según se aprecia en el gráfico 4, la mayor velocidad de degradabilidad de proteínas se presenta en las primeras 0 a 6 horas de incubación, durante las 12, 24, 36 y 48 horas la degradabiidad es proporcional $y$ relativamente menor a las primeras horas; sin embargo, en las 72 y 96 horas la degradación de proteínas son menores y evidencia una tendencia a que la degradabilidad llegó al máximo límite.

La mayor velocidad de degradación puede atribuirse a la selectividad de las partes de plantas consumidas. Las hojas contienen frente a los tallos, más proteína bruta y menos carbohidratos y sustancias indigestible; las proteínas presentes en el alimento, posiblemente, primero son atacados por enzimas de microorganismos del primer y segundo compartimento y las proteínas no fermentadas $o$ no digeridas por los microorganismos se digieren en el tercer compartimento y en el intestino delgado por enzimas digestivas del animal.
Para las llamas la calidad proteica de los alimentos no es importante, según Novoa, (1991) a nivel del primer y segundo compartimento, los microorganismos prefieren el amoniaco como fuente de nitrógeno, teniendo origen por la degradación de proteína bruta de los alimentos, nitrógeno no proteico (NNP) y el reciclado de la urea corporal, estos microorganismos fermentan el contenido fibroso del alimento para obtener energía para sintetizar proteína microbiana a partir de una amplia variedad de fuentes de nitrógeno.

Los resultados reportados por Ancasi, (2013), para Nassella pubiflora en los meses de junio, julio y agosto; la mayor velocidad de degradación de proteína se realiza entre las 0 y 24 horas con 14,01\%, 14,86\%, 14,58\% y $57,9 \%, \quad 57,71 \%, \quad 58,3 \%$ respectivamente, seguido de 48 horas con 71,00\%, 70,25\% y $70,10 \%$, luego la degradación la proteína cruda disminuye. Estos resultados son superiores a los obtenidos en este estudio. 


\section{Degradabilidad in situ de la fibra detergente neutra de la dieta seleccionada por llamas}

Una de las características principales de la fibra, principalmente respecto a los forrajes es eficaz en promover la actividad física de motor del tracto gastro-intestinal.

Tabla 6. ANVA para la degradabilidad in situ de la fibra detergente neutra de la dieta seleccionada por llamas

\begin{tabular}{lrrrrr}
\hline Fuente & G.L. & S.C. & C.M. & Fc. & Pr $>$ F \\
\hline Meses & 2 & 182 & 91 & 17,38 & $<, 0001^{* *}$ \\
Tiempos de fermentación & 7 & 15.322 & 2.189 & 417,65 & $<, 0001^{* *}$ \\
Interacción & 14 & 276 & 20 & 3,76 & $0,0003^{* *}$ \\
Error experimental & 48 & 252 & 5 & & \\
\hline TOTAL & 71 & 16031,58 & & & \\
\hline
\end{tabular}

C.V. $=7,80 \%$

En el análisis de varianza (tabla 6), los resultados muestran que los factores meses y tiempos de fermentación $(\mathrm{p}<0,01)$ afectan en la degradación de fibra detergente neutra en el compartimento 1 de las llamas. El coeficiente de variación de 7,80\%, indica la confiabilidad de los datos obtenidos en la presente investigación.

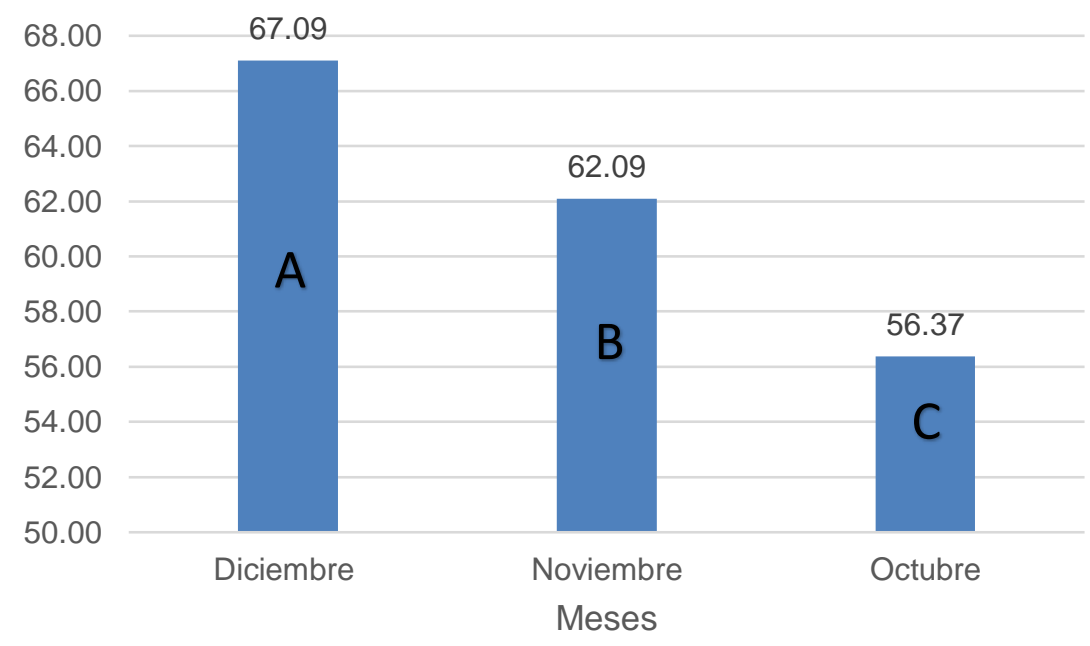

Gráfico 5. Comparación de medias Duncan de la degradabilidad in situ de fibra detergente neutra de la dieta seleccionada por llamas según meses.

Según el gráfico 5, la degradabilidad de fibra detergente neutra del mes de diciembre es superior con $67,09 \%$ con respecto al mes de noviembre con $62,09 \%$, y en el mes de octubre es inferior con $56,37 \%$. 
Esta diferencia se puede atribuir a que la digestibilidad del FDN en forrajes está relacionado con la madurez y el cambio en la relación hoja-tallo. La FDN en hojas de leguminosa o pasto es significativamente más digestible que la FDN del tallo. Conforme el forraje madura, la relación hoja - tallo disminuye (más tallos, menos hojas) y como resultado la digestibilidad de la FDN baja porque una porción más grande del total de FDN es asociada con tejido del tallo.

Con el avance de la madurez, todas las plantas, incluyendo pastos, leguminosas, maíz, y granos pequeños, sufren cambios fisiológicos. Con el avance de la madurez, las plantas desarrollan tejido de xilema para el transporte de agua, acumulan celulosa, y otros carbohidratos complejos, y estos tejidos llegan a enlazarse a través de un proceso conocido como lignificación. El efecto combinado de cambios fisiológicos resulta en la pared celular de las plantas (FDN), la cual es más difícil para la bacteria ruminal de adherirse y digerir (Chursch, 1994).

Los valores encontrados durante la investigación son superiores a los reportados por San Martín (1999), de 42\% de digestibilidad de fibra detergente neutra para raciones de mediana y baja calidad.

Conforme los forrajes maduran, acumula más material indigestible, lo cual decrece el contenido de energía del forraje y la FDN que se está acumulando está siendo menos digestible.

Tabla 7. Comparación de medias Duncan de la degradabilidad in situ de FDN de la dieta seleccionada por llamas según tiempos de fermentación

Grupo Duncan

Media (\%) Factor tiempos de fermentación (Hrs)

A

A B

B

C

D

E

F

G
44,71

43,37

41,37

37,39

28,72

22,13

17,22

0,00
96

72

48

36

24

12

6

0
La degradación de la fibra detergente neutra (Tabla 7), a las horas 72 y 96 son similares con $44,71 \%$ y $43,37 \%$, y superiores a las 48 horas de incubación que esta a su vez es similar a las 72 horas con $41,37 \%$ respectivamente, luego le siguen las 36 horas con $37,39 \%$; 24 horas con $28,72 \%$ y 12 horas con $22,13 \%$, y a las 6 horas de incubación es inferior con $17,22 \%$. 


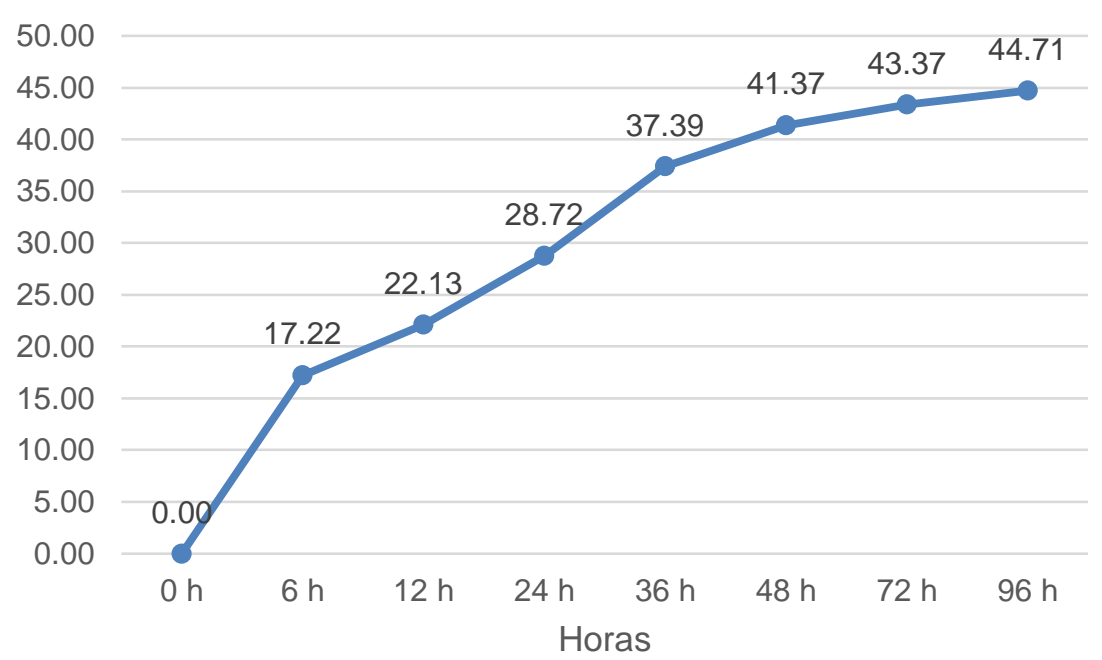

Gráfico 6. Comparación de medias Duncan de la degradabilidad in situ de fibra detergente neutra de la dieta seleccionada por llamas según tiempos de fermentación.

En el gráfico 6 la mayor degradabilidad de fibra detergente neutra ocurre entre 0 a 6 horas de fermentación, le sigue de 12 a 36 horas con una degradabilidad homogénea en este período, y a partir de las 48 horas disminuye la frecuencia de la degradabilidad con tendencia a estabilizarse desde las $72 \mathrm{y}$ 96 horas.

Los resultados reflejan que el proceso de la degradabilidad de FDN es lento y se digiere progresivamente hasta las 48 horas de incubación, la misma que posiblemente se debe a que la dieta seleccionada contiene más gramíneas. Entre las 72 y 96 horas disminuye la velocidad de degradabilidad de FDN porque disminuye la fibra digerible.

La FDN incluye celulosa, hemicelulosa y lignina, además de residuos de nitrógeno y minerales. Las gramíneas se digieren más lentamente que las leguminosas, aunque la degradación total puede llegar a ser mayor que las leguminosas. El motivo de esta aparente discrepancia es que las gramíneas son más ricas que las leguminosas en hemicelulosa y las leguminosas son más ricas en lignina que las gramíneas (Bach $\mathrm{y}$ Calsamiglia, 2006).

La mayor preferencia de selectividad de las especies gramíneas por las llamas fistuladas a nivel esofágico, se presume a las diferencias del grado de palatabilidad que son amplias y comunes entre las especies ramoneables según (Tejada, 1995).

Los resultados de la presente investigación son inferiores a los obtenidos por Molina (1985) de 77,3 \% para degradabilidad de FDN, Huisa y Bryant (1985), de 66,6\% en alpacas en bofedal en época verde y Ancasi (2013) para Nassella pubiflora, en los meses de junio 80,00\%; julio $80,3 \%$ y agosto $79,3 \%$.

Las llamas aprovechan mejor los pastos fibrosos. A esto se suma su gran habilidad de ramonear debido a la fácil movilidad de sus labios y la longitud de su cuello, que le permite alcanzar con menos dificultad que un ovino y bovino a cualquier brote de los arbustos. 
Tabla 8. ANVA de efectos simples para la interacción meses por tiempos de fermentación en la degradabilidad in situ de fibra detergente neutra de la dieta seleccionada por llamas.

\begin{tabular}{|c|c|c|c|c|c|}
\hline F. de V. & G.L. & S.C. & C.M. & F.c. & F. 0,05 \\
\hline Meses (0 hrs) & 2 & $2,34 \mathrm{E}-22$ & $1,17 \mathrm{E}-22$ & 0 & $1,000 \mathrm{NS}$ \\
\hline Meses (6 hrs) & 2 & 1,344 & 0,672 & 0,130 & $0,880 \mathrm{NS}$ \\
\hline Meses (12 hrs) & 2 & 19,901 & 9,950 & 1,900 & $0,161 \mathrm{NS}$ \\
\hline Meses (24 hrs) & 2 & 13,208 & 6,604 & 1,260 & $0,293 \mathrm{NS}$ \\
\hline Meses (36 hrs) & 2 & 29,625 & 14,812 & 2,830 & $0,069 \mathrm{NS}$ \\
\hline Meses (48 hrs) & 2 & 114,668 & 57,334 & 10,940 & 0,000 ** \\
\hline Meses (72 hrs) & 2 & 136,348 & 68,174 & 13,010 & $<, 0001^{* *}$ \\
\hline Meses (96 hrs) & 2 & 142,962 & 71,481 & 13,640 & $<, 0001^{* *}$ \\
\hline Tiempos de fermentación (octubre) & 7 & $6.707,302$ & 958,186 & 182,830 & $<, 0001^{* *}$ \\
\hline Tiempos de fermentación (noviembre) & 7 & $4.205,657$ & 600,808 & 114,640 & $<, 0001^{* *}$ \\
\hline Tiempos de fermentación (diciembre) & 7 & $4.684,899$ & 669,271 & 127,700 & $<, 0001^{* *}$ \\
\hline Error & 48 & 251,565 & 5,241 & & \\
\hline
\end{tabular}

Según el análisis de varianza de efectos simples (Tabla 8), muestra que la degradabilidad de la fibra detergente neutra se encuentra influida por los tiempos de incubación de 48, 72 y 96 horas de fermentación por los meses de octubre, noviembre y diciembre.

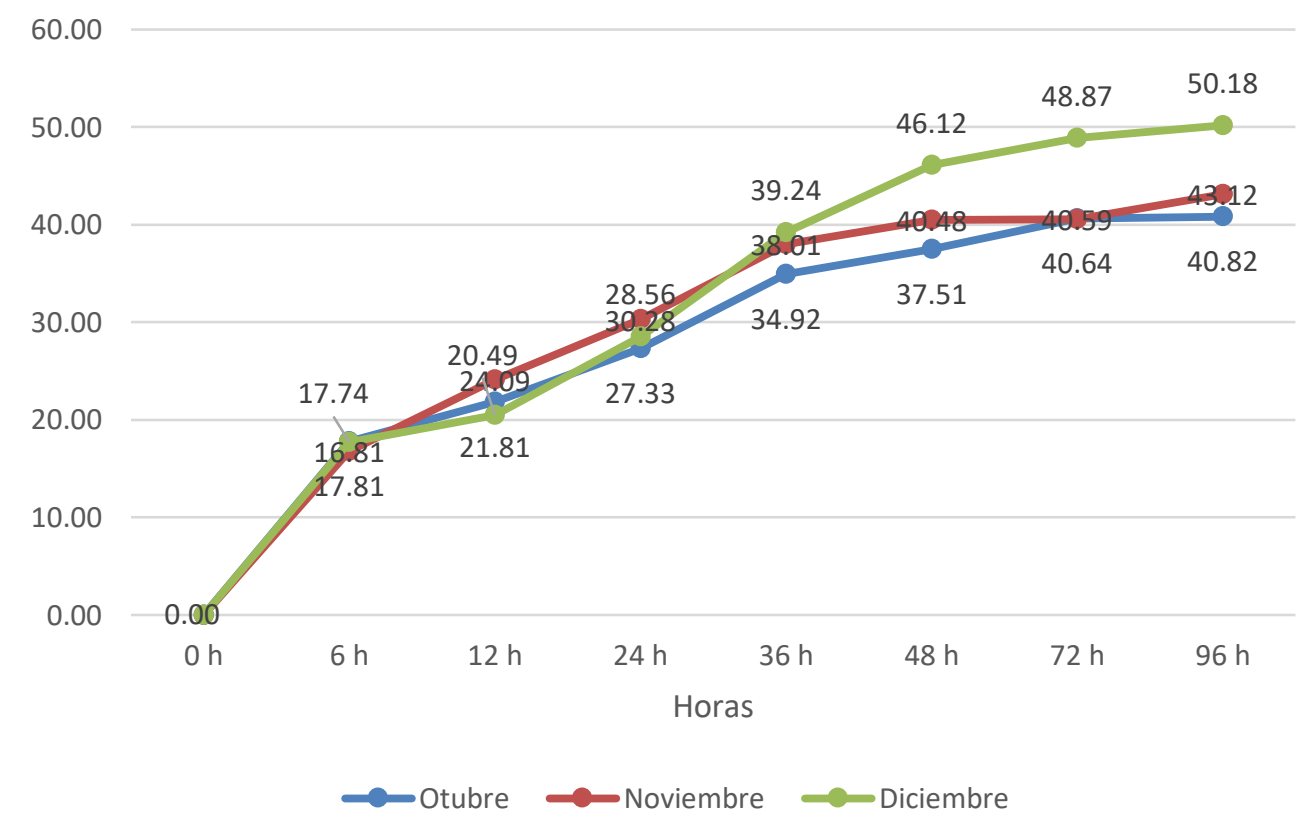

Grafico 7. Efecto de interacción meses de evaluación por tiempos de fermentación sobre la degradabilidad in situ de FDN en la dieta seleccionada por llamas. 
El gráfico 7, muestra que la mayor degradabilidad de la fibra detergente neutra ocurre en el mes diciembre durante 48, 72 y 96 horas con 46,12\%; 48,87\% y 50.18\% respectivamente; en los meses de octubre y noviembre la degradación de FDN son similares e inferiores con 37,51\%; 40,64\%; $40,82 \% \quad$ y $\quad 40,48 \% ; \quad 40,59 \% ; \quad 43,18 \%$ respectivamente.

Los menores niveles de degradabilidad de FDN observadas durante los meses de octubre y noviembre, posiblemente se deban a que los pastos se encuentran en un estadio de madurez fisiológica con la consecuente disminución de fibra digerible (celulosa y hemicelulosa) e incremento de la lignina. Durante el mes de diciembre por la presencia de lluvias existe el rebrote de pastos que contribuye en el incremento progresivo de la digestibilidad de la FDN entre las 48 y 96 horas de fermentación.

Van Soest (1982) afirma que el aumento en el tiempo de retención podría producir mayor degradabilidad a su vez el tiempo de retención está relacionado con el tamaño del animal que depende del tamaño de su tracto digestivo, por tanto los animales mayores tendrían mayores posibilidades de aprovechar mejor los alimentos que los animales menores.

El consumo voluntario está determinado por factores que provienen tanto del alimento como del animal Allen, (1997). Estos factores actúan de manera física o metabólica; sin embargo, por el tipo de dieta habitual de los camélidos sudamericanos, se postula que el factor físico es determinante y, por lo tanto, el contenido de la pared celular o FDN del alimento es la fracción que debe tener un rol importante.

La fibra vegetal es la estructura que les da dureza y rigidez a las plantas, es el componente principal de los tallos de gramíneas y otras. Los glúcidos estructuras complejas (celulosa y hemicelulosa) se encuentran encerrados en las paredes de las células haciéndolos inaccesibles a los animales no rumiantes; sin embargo la población de microorganismos que se encuentran en el primer compartimento de los camélidos le permiten obtener energía de los alimentos fibrosos (Acho, 2003).

\section{Degradabilidad in situ de la fibra detergente ácida de la dieta seleccionada por llamas}

La fibra detergente ácida, está constituida fundamentalmente por celulosa y la lignina, además de residuos de nitrógeno y minerales (Bach, A.; Calsamiglia, S. 2006). Su importancia radica en que está inversamente correlacionada con la digestibilidad del forraje.

Tabla 9. ANVA para la degradabilidad in situ de la fibra detergente ácida de la dieta seleccionada por llamas

\begin{tabular}{lrrrrr}
\hline Fuente & G.L. & S.C. & C.M. & Fc. & Pr > F \\
\hline Meses & 2,000 & 2,751 & 1,375 & 0,370 & 0,6897 NS \\
Tiempos de fermentación & 7,000 & 9778,322 & 1396,903 & 380,200 & $<, 0001^{* *}$ \\
Interacción & 14,000 & 60,606 & 4,329 & 1,180 & 0,3218 NS \\
Error experimental & 48,000 & 176,358 & 3,674 & & \\
\hline TOTAL & 71 & $10.018,036$ & & & \\
\hline C.V. 8,38\% & \multicolumn{7}{c}{}
\end{tabular}


Según el análisis de varianza (tabla 9), la degradación de la fibra detergente ácida se encuentra influida por el factor tiempos de fermentación $(\mathrm{P}<0,01)$. El coeficiente de variación de $8,38 \%$ indica que los datos obtenidos en el presente trabajo son confiables.

Tabla 10. Comparación de medias de Duncan para degradabilidad in situ de FDA (\%) de la dieta seleccionada por llamas según tiempos de fermentación.

\begin{tabular}{|c|c|c|}
\hline Grupo Duncan & Media (\%) & Factor tiempos de fermentación (Hrs) \\
\hline A & 34,95 & 96 \\
\hline $\mathrm{AB}$ & 34,17 & 72 \\
\hline B & 32,48 & 48 \\
\hline $\mathrm{C}$ & 30,16 & 36 \\
\hline $\mathrm{D}$ & 21,77 & 24 \\
\hline E & 16,79 & 12 \\
\hline $\mathrm{F}$ & 12,57 & 6 \\
\hline G & 0,00 & 0 \\
\hline
\end{tabular}

La degradación de fibra detergente ácida (tabla 10), a las 96 y 72 horas son similares y superiores con $34,95 \%$ y $34,17 \%$ con respecto a las 48 horas con $32,48 \%$ que a su vez es similar a las 72 horas de incubación, seguida de 36 horas con 30,16\%; 24 horas con 21,77\% y 12 horas con $16,79 \%$, con menor porcentaje de degradabilidad se da a las 6 horas con 12,57\%.

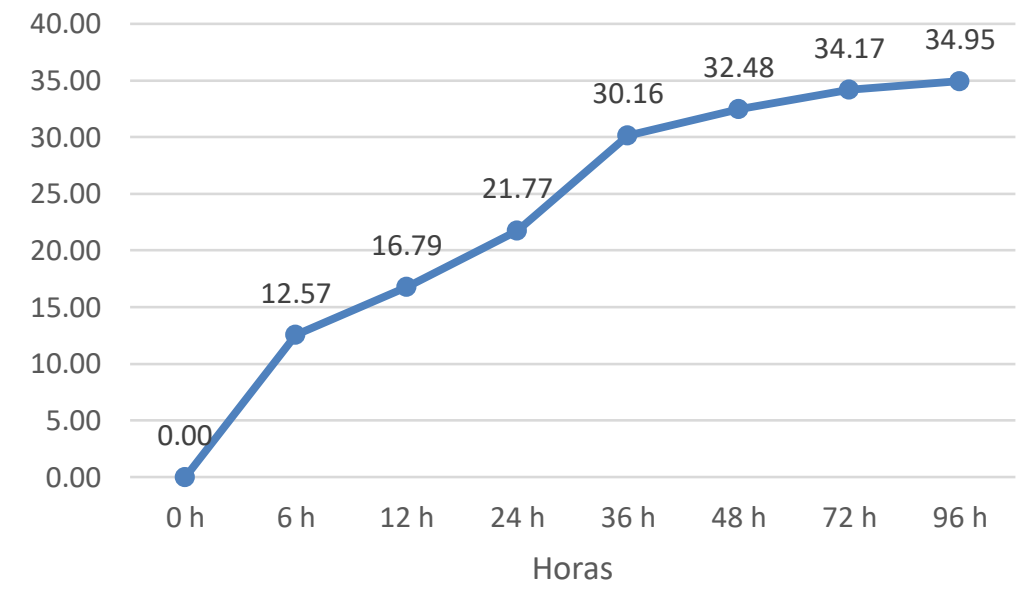

Gráfico 8. Comparación de medias de Duncan para degradabilidad in situ de fibra detergente ácida (\%) de la dieta seleccionada por llamas según tiempos de fermentación

Según se muestra en el gráfico 8, la mayor velocidad de degradación de la fibra detergente ácida se da entre las 6 a 36 horas de incubación, a partir de las 36 horas la velocidad de degradación de FDA disminuye con una tendencia a estabilizarse a partir de las 72 y 96 horas de fermentación. 
Los resultados del presente trabajo, indican que la degradabilidad de fibra detergente ácida es bajo y se realiza a una velocidad muy lento. Esta característica se debe a que solo la parte digerible (celulosa) de la FDA es atacada por los microorganismos del compartimento 1 de las llamas, y no así la lignina que es indigerible. La mayor retención de los pastos en el estómago de las llamas brinda más tiempo a los microrganismos que degradan la fibra vegetal.

El principal componente de la FDA es la lignina, un polímero de alcoholes de hidroxicinamil que es totalmente indigestible en el tubo digestivo de los rumiantes. La lignina es totalmente indigestible, y por ello las leguminosas son menos digestibles; pero la hemicelulosa de las gramíneas presenta numerosas uniones con la lignina que hacen que su ritmo de fermentación sea muy lento, aunque su digestión potencial total sea mayor que en las leguminosas (Bach y Calsamiglia, 2006).

La fibra puede ser degradada únicamente en el rumen y el grado de lignificación de la pared celular es una de las principales limitantes a la digestión. La estructura física de la pared celular y cómo se relacionan la lignina con la celulosa y la hemicelulosa también afecta la degradación ruminal de la fibra. Por lo tanto, a pesar que las leguminosas poseen un mayor contenido de lignina que las gramíneas, estas últimas poseen una menor tasa de digestión de la pared celular a causa de la forma en que la lignina se relaciona con la celulosa y la hemicelulosa, provocando un mayor llenado ruminal $\mathrm{y}$ en consecuencia un menor consumo (Palladino, et al. 2006)

Las fibras con alto contenido de celulosa, lignina y hemicelulosa, ocupan mayor espacio en el estómago y producen menos energía para el animal (Carpenter, 2013).
Los resultados de la degradablidad in situ de la fibra detergente ácida encontrados en la presente investigación, resultan ser inferiores, a los reportados por Ancasi (2013) para Nassella pubiflora en los meses de junio, julio y agosto con $39.01 \%$, 39.25\% y $39.81 \%$ de digestibilidad fibra detergente ácida para 96, 72 y 48 horas de fermentación respectivamente.

\section{CONCLUSIONES}

De acuerdo a los resultados obtenidos en este estudio, se llegó a las siguientes conclusiones:

La degradabilidad in situ de la materia seca de la dieta seleccionada por las llamas fue superior en los meses de noviembre y diciembre e inferior en octubre, superior a 96 y 72 horas y menor a 0 horas de fermentación $(\mathrm{P}<0,01)$, la velocidad de digestión de la materia seca se da en un proceso lento $y$ progresivo alcanzando a niveles mayores hasta las 72 horas de incubación y luego disminuye los niveles de digestión. Los pastos son menos digeribles en el mes de octubre por su estado de madurez fisiológica y están secos por efectos del clima.

La degradabiliad in situ de proteína bruta son influidas por el tiempo de fermentación, superior a las 96 y 72 horas de incubación, seguido de manera proporcional entre 36 a 6 horas, e inferior a las 0 horas $(\mathrm{P}<0,01)$; la mayor velocidad de degradación se presenta en las primeras 0 a 6 horas, seguido de 12 a 48 horas y disminuye desde las 72 horas. Estos niveles de degradación se deben a que las llamas consumen de manera selectiva hojas de plantas que contienen proteínas.

La degradabilidad in situ de FDN es superior en diciembre seguido por noviembre e inferior en octubre; superior a las 96 y 72 horas de fermentación, seguido entre las 48 a 12 horas e inferior a las 6 horas de incubación 
$(\mathrm{P}<0.01)$, la velocidad de degradación es lento siendo superior entre 0 a 6 horas de incubación, le sigue de 12 a 36 horas y disminuye a partir de 48 horas. Los niveles de la degradación de FDN están relacionados con el estado fenológico de los pastos, a medida que los pastos maduran la relación hoja-tallo disminuyen e incrementa la lignina que baja su digestibilidad.

La digestibilidad in situ de fibra detergente ácida es superior a las 96 y 72 horas de fermentación, seguido entre las 48; 36; 24 y 12 horas, e inferior a las 6 horas de incubación $(\mathrm{P}<0,05)$; la mayor velocidad de degradación se da entre las 6 a 36 horas de incubación, y disminuye después de las 36 horas. La degradación de FDA es bajo y en un proceso muy lento, debido a que sólo la celulosa parte digerible de la fibra es atacada por los microorganismos y no la lignina que es fibra indigerible.

La degradabilidad in situ de la dieta seleccionada por las llamas, se da en un proceso y velocidad lento por las características y estado de la estructura física de la pared celular y cómo se relacionan la lignina con la celulosa y la hemicelulosa, y estas afectan la degradación en los nutrientes. Para maximizar la digestión se requiere mayor retención de la digesta, situación presente en el compartimento 1 del estómago de las llamas, que se caracteriza en una tasa de pasaje lento de los alimentos.

\section{REFERENCIAS}

Acho, M. (2003). Degradabilidad in situ de pradera nativas en llamas (Lama glama) en época lluviosa en la comunidad Pujrata - Provicia Pacajes, Universidad Católica San Pablo, carrera de Ingeniería Zootécnica Unidad Académica Campesina Tiahuanaco Tesis de Grado La Paz Bolivia Allen, M.S. (1997). Relationship between fermentation acid production en the rumrn and the requirement por phisically effective fiber. J. Dairy Sci. 80: 1447-1462

Ancasi, T. D. (2013). Degradabilidad in situ del pasto nativo (nassella publiflora) en llamas (lama glama) en epoca seca en la comunidad jilauta manasaya de la provincia sajama, Oruro, Universidad Pública de El Alto, carrera de Medicina Veterinaria y Zootecnia, Tesis de Grado La Paz Bolivia

Ayala, G. y B. Aranda, (1999). Manual de manejo y Conservación de Praderas nativas Dto. de Capacitación y Manejo de RR.NN. strategies for International Development SID. La Paz, Bolivia $56 \mathrm{p}$

Bach, A. y Calsamiglia S. (2006). Grupo de investigación en nutrición, manejo y bienestar animal. IRTA - Unidad de Rumiantes. Universidad Autónoma de Barcelona.

Bautista. J. 1999. Fistulacion y Canulacion de animales Facultad de Medicina Veterinaria y Zootecnia, universidad Nacional del Altiplano Puno Perú.12-19 pp

Cardozo, A., (2007). Camélidos. Primera Edición. Cochabamba - Bolivia 69 p

Cardozo, A. (1991). Proyección de la ganadería ovina y camélida en el departamento de Oruro, Academia Nacional de Ciencias La Paz. Bolivia 145 p

Carpenter M., E., (2013). Differences Between an Acid Detergent Fiber \& a Neutral Detergent Fibe

Church, G. (1994). Bases científicas para la nutrición y alimentación de los animales domésticos, Editorial Acribia, Zaragoza, España. $462 \mathrm{p}$

Choque, N. S. Y Magne, R. J. (1996). Utilización del iru wichu (Festuca orthophylla) como forraje de emergencia. Programa de Promoción Social y Desarrollo Agrario (PRODAS), Instituto Francés de Investigación Científica para el Desarrollo en Cooperación. QUELCO. Oruro - Bolivia. $41 \mathrm{p}$

FAO, (2005). Situación Actual de los Camélidos Sudamericanos en Perú. (Organización de las Naciones Unidas para la Agricultura y la Alimentación) FAO. Perú. 15 - 47 pp 
Huisa. T.; Farfan, R. Y Bryant, F. (1985). Composición botánica de la dieta de alpacas durante la época seca IVITA. UNMSM. VIII Reunión científica animal. Asociación de producción animal Universidad Nacional de centro del Perú Huancayo - Perú

Molina, P., A. (1985). “Digestibilidad en llamas alimentadas con pradera nativa dominados por Festuca dolichophylla, Alchimilla pinnata, Mulimbergia fastigiata". UNA - PUNO. Puno - Perú

Novoa, C. (1991). Fisiología de la reproducción de la hembra, avances y perspectivas de los conocimientos de los camélidos sudamericanos FAO. Santiago, Chile. Pp.94-102.

Nova, C. y Flores, A. (1991). Producción de rumiantes menores. Imprenta Martegraf. Lima - Perú

Palladino A., Wawrzkiewicz M. y Bargo F. 2006. Infortambo, Bs. As., 202:82-84. Departamento de Producción Animal, Facultad de Agronomía, UBA

PDM. H.A.M.C.C. (2007-2011). Plan de Desarrollo Municipal. Honorable Alcaldía Municipal de Curahuara de Carangas, Oruro, Bolivia. 214 - 300 pp

Rodríguez, C. Y Cardozo, A. (1989). Estado de la Ganadería andina en Bolivia Universidad Mayor de San Andrés, Facultad de Agronomía La Paz, Bolivia. $180 \mathrm{p}$
San Martin, F. (1999). Alimentación y nutrición Avances y perspectivas del conocimiento de los camélidos sud Americanos. S. Fernández Vaca Ed. Oficina regional de la FAO. Para la América Latina y el Caribe Santiago Chile. 213 - 228 pp

SENASAG Catastro Pecuario, (2011). Servicio Nacional de Sanidad Agropecuaria e Inocuidad Alimentaria; Ministerio Desarrollo Rural y Tierras. La Paz Bolivia.7- 8 pp.

Solís, R. (2000). Producción de camélidos sudamericanos. Imprenta Ríos S. A. Primera Edición. Huancayo - Perú

Tejada, E. (1995). Políticas para el desarrollo sostenible del recurso camélido. Impresores Artes Gráficas Latina. La Paz Bolivia

Ticona, L., Defilippis, D. (1995). Lineamientos de políticas Para el Desarrollo sostenible del recurso Pecuario- Seminario Taller Nacional. La Paz - Bolivia.16- 46 pp

Van Soest, Pj (1982). Ecología nutricional de los rumiantes. C.U.P., Ithaca, NY

Villca, C., R., D. (2013). Composición botánica y química de la ingesta seleccionada por la llama (lama glama) en la comunidad jilauta manasaya, provincia sajama, oruro 2013. Universidad Pública de El Alto, carrera de Medicina Veterinaria y Zootecnia, Tesis de Grado La Paz Bolivia 